\title{
Ophthalmological changes after posterior spine surgeries: A prospective study
}

\author{
Karthik Jain M. ${ }^{1}$, Bindu George ${ }^{2, *}$, Fonseca Alex Jude ${ }^{3}$, Deleema D. ${ }^{4}$, Ann Mary ${ }^{5}$ \\ ${ }^{1}$ Associate Professor, ${ }^{2}$ Professor, ${ }^{3,5}$ Resident, ${ }^{4}$ Senior Resident,,${ }^{1,2,3}$ Dept. of Anaesthesia, ${ }^{4,5}$ Dept. of Ophthalmology, St. John's \\ Medical College, Bangalore, Karnataka, India
}

*Corresponding Author:

Email: bindu575@gmail.com

Received: $12^{\text {th }}$ September, 2017

Accepted: $01^{\text {st }}$ February, 2018

\begin{abstract}
Introduction: Postoperative visual loss (POVL) after posterior approach to spine surgeries is a devastating complication necessitating a prospective study. The primary aim was to identify ophthalmological changes contributing to POVL (visual acuity, anterior segment, intraocular pressure (IOP), fundus, field of vision, external ocular examination). Secondary objectives was to evaluate the relationship between ophthalmological changes and various perioperative data including patient comorbidities, positioning and other intraoperative details.

Materials and Methods: After getting necessary approvals and consent, thirty patients posted for the posterior spine surgeries were assessed preoperatively. Ophthalmological examination was conducted preoperatively, the day before surgery and postoperatively twice (first within an hour of completion of surgery and second at twenty four hours). Perioperatively, data including type of surgical frame, headrest used, duration of prone positioning, total blood loss, total intravenous fluids administered, lowest mean arterial pressure for more than ten minutes, blood transfusion details and use of hypotensive anaesthesia were noted. Data were analyzed using chi-square test, paired t test, and correlation coefficient.

Results: There were no changes in visual acuity, anterior segment, fundus and field of vision postoperatively. But 12 patients had a rise in IOP and six developed lid edema and chemosis. There was a minimal increase in IOP at one hour post operatively (right eye- $2.8 \mathrm{~mm} \mathrm{Hg}(\mathrm{p}=0.001$, and left eye- $3 \mathrm{mmHg}(\mathrm{p}<0.001)$. The analysis of perioperative data revealed no relationship with ophthalmological changes noted.

Conclusion: There were no clinically significant ophthalmological changes contributing to POVL in spine surgeries in prone position. Observed ophthalmological changes did not have any correlation with patient comorbidities, positioning and other intraoperative details.
\end{abstract}

Keywords: Intraocular pressure, Chemosis, Postoperative visual loss, posterior spine surgery, Prone position.

\section{Introduction}

Postoperative visual loss (POVL) in nonophthalmic surgeries is a devastating complication with an incidence ranging from $0.2-4.5 \% .^{1,2}$ In spine surgeries in prone position, the incidence is 0.1 $0.2 \%{ }^{1,3}$ According to the American Society of Anesthesiologists (ASA) Postoperative Visual Loss Registry, most common causes of POVL in spine procedures are anterior and posterior ischemic optic neuropathy, both of which together account for $89 \%$ of the cases. ${ }^{4,5,6}$ Retinal ischemia, cortical blindness, and posterior reversible encephalopathy are also observed in a minority of cases.

Most of the studies have been retrospective in nature and with little data on what occurs in the immediate post-operative period. Various risk factors have been elucidated by analysis of data available but with a time $\operatorname{lag}^{5-11}$ and inadequate preoperative data. In addition there might be bias against reporting these data. The irreversible nature of this devastating complication necessitates a prospective study to analyze the clinical findings at the earliest. The primary objective of our study was to identify early ophthalmological changes contributing to POVL (visual acuity, anterior segment, intraocular pressure, fundus, field of vision, external ocular examination) in patients undergoing posterior spine surgeries by preoperative and postoperative examination (with the null hypothesis that "no opthalmological changes causing POVL occur in spine surgeries in prone position'). Secondary objectives was to evaluate the relationship between the observed ophthalmological changes and various perioperative data including patient comorbidities, positioning and intraoperative details.

\section{Materials and Methods}

After getting Institutional ethical committee approval for a preliminary(observational) study on 30 patients and obtaining written consent from all patients(ASA grading- one to three) posted for posterior thoracic or lumbar spine surgeries, preoperative assessment was done by detailed clinical history and physical examination. Patients with history of cardiac arrest, cerebro-vascular accident and patients with gross ophthalmological changes (corneal opacity, blindness, pthysis bulbi) were excluded. Demographic parameters (age, sex, height and weight) and presence of co-morbid illnesses (diabetes mellitus, hypertension, coronary artery disease, obesity) were noted. Ophthalmological examination was conducted by an Ophthalmologist with more than two years experience, preoperatively the day before the surgery, postoperatively twice - first 
within an hour (hr) of completion of surgery and second at twenty four hrs post operatively which was inclusive of the following: 1. Visual acuity (using snellen's visual acuity chart) 2. Anterior segment examination (including pupillary reflexes) 3. Intraocular pressure (IOP) (using hand held perkin's applanation tonometer after topical application of paracaine eye drops and fluorescein dye) 4. Fundus examination (by indirect ophthalmoscopy) 5. Field of vision testing (by confrontation method) 6.External ocular examination.

Patient monitors included electrocardiography, pulseoximetry, non-invasive blood pressure, end-tidal carbon dioxide $\left(\mathrm{Et} \mathrm{CO}_{2}\right)$, peak airway pressure, urine output. Anesthesia was induced with injection fentanyl 2 micrograms $/ \mathrm{kg}$ and injection propofol $1-2 \mathrm{mg} / \mathrm{kg}$ and endotracheal intubation was done after injection atracurium $0.5 \mathrm{mg} / \mathrm{kg}$. Isoflurane and nitrous oxide, $50 \%$ in oxygen was used for maintenance of anesthesia with intermittent doses of injection atracurium. Ventilation was adjusted to maintain $\mathrm{EtCO}_{2}$ between 30 and $35 \mathrm{mmHg}$. After induction of anesthesia patients were positioned prone with precautions to prevent compression of eyeball and abdomen. Occlusive eye padding and manual checking was done to ensure that eyes are free of any compression. The type of surgical frame and headrest used were noted. Intraoperatively duration of prone positioning, total blood loss, total intravenous fluids administered, lowest mean arterial pressure (MAP) for more than ten minutes, blood transfusion details, and use of hypotensive anesthesia were noted. Individual anesthetic plan such as use of hypotensive anesthesia, type of headrest (horseshoeFigure 1 or ring headrest-Figure 2), surgical frame (relton-hall frame-Figure 3 or cushion pads-Figure 4) was left to the discretion of the concerned anesthesiologist.

\section{Statistical analysis}

Incidence of ocular changes was reported using proportion and percentage. Clinical and demographic factors associated with each ocular change were analyzed using chi-square test. Mean change in IOP value from baseline was noted. Preoperative and postoperative mean IOP values were compared using paired t test. The relationship between the mean change in IOP with various perioperative data (including patient comorbidities, positioning and intraoperative details) was done using correlation coefficient. $\mathrm{P}$ values less than $5 \%$ was considered as statistically significant.

\section{Results}

Table 1: IOP changes
Majority of the patients underwent two level lumbar posterior decompression \& fixation. In the study population, $63.3 \%$ subjects were females and mean age of participants was $46.7 \pm 10.9 y$ rs with mean weight of $63.1 \pm 10.9 \mathrm{kgs}$. Mean body mass index of the participants was $24.7 \pm 3.8$. In the study population, five patients were diabetic, eight were hypertensive, one had history of coronary artery disease and two were obese.

There were no changes in visual acuity, anterior segment, fundus and field of vision postoperatively. Chemosis and lid edema were noted in six patients (20\%) on first postoperative examination (within an hour) and had resolved in five of them by 24 hours as found during second postoperative examination. All of these six patients had rise in IOP. Increase in mean IOP was noted in both eyes during both postoperative examinations, but was statistically significant only during first examination $(\mathrm{p}=0.001$ for right eye and $\mathrm{p}<0.001$ for left eye). Baseline IOP was 13.9 \pm 2.7 $\mathrm{mmHg}$ and $13.5 \pm 2.9 \mathrm{mmHg}$ in right and left eyes respectively. It increased to $16.7 \pm 4.2$ and $16.5 \pm 4.1$ during first postoperative examination and decreased to $14.5 \pm 2.9 \mathrm{mmHg}$ and $14.7 \pm 2.9 \mathrm{mmHg}$ during second postoperative examination in right and left eyes respectively (Table 1). The mean increase in IOP on first postoperative examination was $2.8 \mathrm{mmHg}$ and 3 $\mathrm{mmHg}$ in right and left eyes respectively. Ventilatory parameters did not change significantly during the surgery.

Regarding surgical frame, cushion pads were used in twenty $(66.7 \%)$ and relton-hall frame was used in ten patients $(33.3 \%)$. Horseshoe headrest was used in 27 patients $(90 \%)$ and ring gel headrest was used in 3 patients $(10 \%)$. Mean duration of patient in prone position was $183.7 \pm 89.1$ minutes and mean blood loss was $525 \pm 241.7 \mathrm{ml}$. Total intravenous fluids administered was $2246 \pm 789.5 \mathrm{ml}$ and blood transfusion (packed cells) was done for two patients(6.7\%). Hypotensive anaesthesia was used in nineteen patients $(63.3 \%)$, and lowest MAP for more than ten minutes was $65.5 \pm 10.1 \mathrm{mmHg}$.

The relationship of perioperative data (patient comorbidities, type of surgical frame and head rest, duration of prone positioning, total blood loss, total intravenous fluids administered, lowest MAP for more than ten minutes, blood transfusion details, use of hypotensive anesthesia) with ophthalmological changes noted during the study (lid edema, chemosis, increase in IOP) which was analyzed using correlation coefficient did not reveal any correlation $(\mathrm{p}>0.05)$.

\begin{tabular}{|l|c|c|}
\hline \multicolumn{1}{|c|}{ Time } & $\begin{array}{c}\text { Left eye (IOP) } \\
\mathbf{m m H g}\end{array}$ & $\begin{array}{c}\text { Right eye (IOP) } \\
\mathbf{m m H g}\end{array}$ \\
\hline Preoperative (Baseline) & $13.53 \pm 2.86$ & $13.87 \pm 2.67$ \\
\hline $\begin{array}{l}\text { First postoperative } \\
\text { examination(within an hour }\end{array}$ & $16.53 \pm 4.06$ & $16.67 \pm 4.21$ \\
\hline
\end{tabular}




\begin{tabular}{|l|l|l|}
\hline of surgery) & & \\
\hline $\begin{array}{l}\text { Second postoperative } \\
\text { examination(at 24 hours) }\end{array}$ & $14.70 \pm 2.93$ & $14.47 \pm 2.90$ \\
\hline
\end{tabular}

\section{Discussion}

The importance of vigilance in surgeries in prone position to avoid direct compression of the eyeball can never be emphasised enough. It is also important to avoid POVL, which can occur in spite of due precautions. Various causes of visual loss in this scenario are anterior and posterior ischemic optic neuropathy (AION and PION respectively), central and branch retinal artery occlusion (CRAO and BRAO respectively), cortical blindness etc. The incidence of posterior ischemic optic neuropathy is more common among the listed causes. The explanations used for ION during these surgeries are the elevation of venous pressure and development of interstitial edema. ${ }^{5,12}$ This can cause damage to the optic nerve by compression of vessels that supply the optic nerve resulting in venous infarction $^{5,12}$. Retinal artery occlusion decreases blood supply to the retina due to improper positioning and external compression on the eye. ${ }^{5,12}$ Cortical blindness is the result of hypoperfusion or embolic phenomenon in the occipital cortex. ${ }^{5,12}$ The diagnosis of each of these conditions can be made clinically by ophthalmological examination. Ophthalmological findings in these conditions could be as follows: 1. painless loss of vision, sectoral or diffuse disc edema, altitudinal field defect in AION, 2. painless visual loss, normal optic disc, altitudinal field defect in PION, 3. Severe vision loss with negative perception of light, pale retina including optic disc, severe attenuation of arterioles, cherry red spot at macula in CRAO, 4. Partial visual loss, sectoral pale retina, sectoral field defect in BRAO. ${ }^{5}$ The treatment in each of the conditions is not effective and mostly results in permanent blindness.

We attempted to look for the signs of pathophysiological changes in the eye post operatively at the earliest. To get an insight into the pathological process, it is important to observe changes that occur in the eyes of patients who do not develop POVL and to see if routine ophthalmological examination is necessary in these patients.

None of our patients had post-operative loss of vision, changes in fundus or field of vision. Lid edema, chemosis and minimal rise in IOP were noted postoperatively. Although rise in IOP during first postoperative examination was statistically significant, the value was not significant clinically. The role of rise in IOP as a causative factor for POVL remains unclear.

Mean increase in IOP during first postoperative examination $(2.8 \mathrm{mmHg}$ in the right eye $(\mathrm{p}=0.001)$ and $3.0 \mathrm{mmHg}$ in the left eye $(\mathrm{p}<0.001))$ was statistically significant for both eyes. During the second postoperative examination, IOP had decreased in both eyes. IOP increase in prone position is noted in other studies as well. The mechanism proposed is the shift of iris-lens diaphragm anteriorly, causing effects similar to angle closure glaucoma. ${ }^{13-15}$ Ocular perfusion pressure (OPP) is commonly defined as mean MAP minus $\mathrm{IOP}^{16}$. Changes in MAP or IOP can affect OPP. An increase in IOP can lower OPP despite maintenance of normal MAP. Therefore, it is important to understand what happens to IOP in prone anesthetized patient.

Mary Ann Cheng et $\mathrm{al}^{13}$ measured IOP in 20 patients scheduled for spine surgery in the prone position. They found that IOP increased from baseline of $19 \pm 1 \mathrm{mmHg}$ to $27 \pm 2 \mathrm{mmHg}$, which increased further to $40 \pm 2 \mathrm{mmHg}$ after $320 \pm 107$ minutes in prone position. IOP on turning supine after completion of surgery (which approximately correlates with our first postoperative examination) was $31 \pm 2 \mathrm{mmHg}$ in their study. Longer time in the prone position was associated with higher IOP measurements. The IOP readings in their study were high compared to our study probably because of longer duration of surgery. Mean duration of surgery in our study was about three hours compared to about more than five hours in their study. Intraoperative ophthalmological examination was not executed in our study, partly because of difficulty in measuring IOP in the prone position during surgery which could have yielded additional valuable information. If duration of surgery was more, we could expect higher IOP reading.

Current consensus among ophthalmologists and optometrists define normal intraocular pressure as that between $10 \mathrm{mmHg}$ and $20 \mathrm{mmHg} .{ }^{17}$ Vieira et al noted that the average value of intraocular pressure is 15.5 $\mathrm{mmHg}$ with diurnal fluctuations of about $2.75 \mathrm{mmHg}{ }^{18}$ The mean increase in IOP observed in our study was slightly more than the diurnal fluctuations. Lid edema and chemosis was noted postoperatively in $20 \%$ of our patients, most of which subsided within the first 24 hours. Thus, these changes were self-limiting.

In the largest and most comprehensive study to date, the Postoperative Visual Loss Group, using data from the ASA Postoperative Visual Loss Registry, identified obesity, male sex, Wilson frame use, longer anesthetic duration ( $>6 \mathrm{hrs}$ ), greater estimated blood loss ( $>1$ litre), and lower percentage of colloid in the nonblood fluid administered as significant independent risk factors for the development of $\mathrm{ION}^{5,6,19}$ which were monitored in our study.

Gender, any pre-existing disease or obesity were not found to be significantly associated with postoperative eye changes observed in our study (lid edema, chemosis, rise in IOP). Most of our cases had blood loss of less than $600 \mathrm{ml}$ and the average duration of surgery was around three hours. There was no significant correlation of noted ophthalmological changes with respect to type of surgical frame, headrest, intravenous fluid administration, blood loss, hypotensive 
anaesthesia, colloid administration possibly due to a smaller sample size.

It appears that perioperative ophthalmological examination may not be needed routinely for all posterior spine surgeries. Also there is a need to evaluate eye changes with further studies in long duration surgeries especially in hypermetropes and patients with angle closure glaucoma because they are prone for further increase in IOP perioperatively. Finally, number of patients in our study was relatively small with respect to the low incidence of post operative visual loss. Nevertheless, both surgeon and anaesthetist need to be aware and vigilant regarding development of opthalmological changes during these surgeries.

\section{Conclusion}

There were no ophthalmological changes in relation to visual acuity, fundus or field of vision postoperatively in posterior spine surgeries. Chemosis, lid edema and minimal rise in IOP observed postoperatively do not appear to contribute to POVL. Also these ophthalmological changes do not have any correlation with other observed variables such as patient comorbidites, positioning details, duration of prone positioning, total blood loss, total intravenous fluids administered or hypotensive anesthesia. Routine perioperative ophthalmological examination may not be needed in posterior spine surgeries. Further studies are needed to substantiate results.

\section{References}

1. Stevens WR, Glazer PA, Kelley SD, Lietman TM, Bradford DS. Ophthalmic complications after spinal surgery. Spine 1997;22:1319-24.

2. Shaw PJ, Bates D, Cartlidge NEF, Heaviside D, French JM, Julian DG, Shaw DA Neuro-ophthalmological complications of coronary artery bypass graft surgery. Acta neurologica scandinavica 1987;76:1-7.

3. Edgcombe H, Carter K, Yarrow S. Anaesthesia in the prone position. British Journal of Anaesthesia 2008; 100:165-83.

4. Nickels TJ, Manlapaz MR, Farag E. Perioperative visual loss after spine surgery. World journal of orthopaedics 2014;5:100-5.

5. Lee LA, Roth S, Posner KL, Cheney FW, Caplan RA, Newman NJ, etal. The American Society of Anesthesiologists postoperative visual loss registry. Anesthesiology 2006;105:652-9.

6. Apfelbaum JL, Roth S, Connis RT, Domino KB, Lee LA, Nickinovich DG, etal. Practice Advisory for Perioperative Visual Loss Associated with Spine Surgery: An Updated Report by the American Society of Anesthesiologists Task Force on Perioperative Visual Loss. Anesthesiology 2012;116:274-85

7. Myers MA, Hamilton SR, Bogosian AJ, Smith CH, Wagner TA. Visual loss as a complication of spine surgery: a review of 37 cases. Spine 1997;22:1325-29.

8. Patil CG, Lad EM, Lad SP, Ho C, Boakye M. Visual loss after spine surgery: a population-based study. Spine 2008;33:1491-96.
9. Murphy MA. Bilateral posterior ischemic optic neuropathy after lumbar spine surgery. Ophthalmology 2003;110:1454-57.

10. Dilger JA, Tetzlaff JE, Bell GR, Kosmorsky GS, Agnor $\mathrm{RC}$, O’Hara JF. Ischaemic optic neuropathy after spinal fusion. Canadian journal of anaesthesia 1998;45:63-6.

11. Matalia J, Rajput VK, Chillal GJ, Shetty BK. Ophthalmic artery occlusion with total ophthalmoplegia following spinal surgery. Neurology India 2015;63:431-5.

12. Lee LA. Postoperative Visual Loss Study Group. Risk factors associated with ischemic optic neuropathy after spinal fusion surgery. Anesthesiology 2012;116:15-26.

13. Cheng MA, Todorov A, Tempelhoff R, McHugh T, Crowder CM, Lauryssen C. The effect of prone positioning on intraocular pressure in anesthetized patients. Anesthesiology. 2001;95:1351-5.

14. Tsamparlakis J, Casey TA, Howell W, Edridge A. Dependence of intraocular pressure on induced hypotension and posture during surgical anaesthesia. Transactions of the ophthalmological societies of the United Kingdom 1979;100:521-26.

15. Yoshimura K, Hayashi H, Tanaka Y, Nomura Y, Kawaguchi M. Evaluation of predictive factors associated with increased intraocular pressure during prone position spine surgery. Journal of anesthesia 2015;29:170-4.

16. Hayreh SS. Anterior ischemic optic neuropathy. Clinical neurosciences 1997;4:251-3.

17. Allingham RR, Karim FD, Sharon F, Sayoko EM, GeorgenS, Bruce SM. Intraocular pressure and tonometry. In:Allingham RR,editor. Shields' Textbook of Glaucoma, $5^{\text {th }}$ ed. Philadelphia. Lippincott Williams \& Wilkins.2005.p.36-39.

18. Vieira GM, Oliveira HB, de Andrade DT, Bottaro M, Ritch R. Intraocular pressure variation during weight lifting. Archives of ophthalmology 2006;124:1251-4.

19. Lee LA. Perioperative visual loss and anesthetic management. Current Opinion in Anesthesiology 2013;26:375-81. 